\title{
El Drama Mestizo y la Recuperación del Sentido en la Acción Colectiva: La Crítica Social Latinoamericana en el Pensamiento de Rodolfo Kusch
}

\section{The drama of mestizo people and the recovery of sense in collective action: The Latin American social criticism in the thinking of Rodolfo Kusch}

0 drama mestiço e a recuperação do significado na ação coletiva: A crítica social latino-americana no pensamento de Rodolfo Kusch

Dr. Cristián Valdés Norambuena'

Recibido: 19/08/2014 - Aceptado: 10/09/2014

\begin{abstract}
Resumen
El presente artículo tiene por objetivo ensayar una interpretación del sentido de la acción colectiva a partir de la obra del pensador argentino Rodolfo Kusch, en vista de explicitar sus fuentes en el siglo XIX, sus repercusiones en el siglo $\mathrm{XX}$, y las posibilidades filosóficas que otorga su idea de "historia como estética".
\end{abstract}

Palabras claves: acción colectiva, política, drama mestizo, historia.

Abstract

This article aims attempting to interpret the meaning of collective action from the work of Argentine thinker Rodolfo Kusch, in order to explicit his sources in the Nineteenth Century, his impact on the Twentieth

\footnotetext{
1 Chileno, Profesor de Filosofía por la Universidad Católica Silva Henríquez, Magíster en Filosofía por la Universidad de Chile y Doctor en Filosofía por la Université Catholique de Louvain, Bélgica. Actualmente se desempeña como profesor en la Universidad Católica Silva Henríquez. Mail de contacto: entevaldes@yahoo.com
} 
Centuryand the philosophical possibilities given by his idea of "history as aesthetic".

Key words: collective action - politics - mestizodrama - history

Resumo

O presente artigo tem como objetivo testar uma interpretação do significado da ação coletiva a partir do trabalho do pensador argentino Rodolfo Kusch, tendo presente a necessidade de explicitar suas fontes no século XIX, seu impacto no século XX, e as possibilidades filosóficas que entrega sua ideia de "história como estética".

Palavras-chave: Ação Coletiva - Política - Drama Mestiço - História.

\section{Introducción}

La intención de este artículo es mostrar la crítica social latinoamericana a partir de los trabajos del pensador argentino Rodolfo Kusch, quien a través de una significativa y penetrante interpretación de nuestros conflictos sociales, muestra aquellas ideas fuerza que durante el siglo XIX importantes políticos e intelectuales del Cono Sur formularon y utilizaron para levantar $y$ sostener discursos e instituciones, esgrimiendo principios de acción y reflexión que en mayor o menor medida aún siguen vigentes en nuestra vida social y política.

El artículo se dividirá en tres momentos: en el primero intentaré dar cuenta de las principales fuentes filosóficas del siglo XIX que nutren una concepción histórica de nuestros países en base a la negación de nuestra autoctonía. En segundo lugar intentaré mostraré lo que Kusch llama el drama mestizo, es decir, las consecuencias silenciosas que ha tenido en el tejido social una disgregación sistemática entre nuestro Ethos y una institucionalidad copiada a partir de modelos importados, para finalizar con la propuesta kuschiana de una historia como estética en vista de abrir caminos de reflexión que nos permitan comprender dichos conflictos sociales en vista de una eventual resolución.

\section{La civilización y la barbarie como ejes de reflexión}

La historia de las ideas latinoamericana durante el siglo XIX, inmediatamente posterior a las guerras de independencia, implica una 
significativa y necesaria reflexión del sentido de la acción política, una vez que separados de la metrópoli aparece el desafío de la consolidación y la proyección de las nuevas repúblicas, principalmente sobre la base de una institucionalidad suficiente que sea capaz de sostenerlas en el tiempo.

Dentro de este contexto propio de las naciones jóvenes, es que se levanta en Latinoamérica una singular discusión respecto del sery del deber ser de nuestros países, que alcanza una de sus manifestaciones más significativas y conocidas en la obra del argentino Domingo Faustino Sarmiento. Su ensayo titulado Facundo o Civilización y Barbarie en las Pampas Argentinas ${ }^{2}$ de 1845 , resulta paradigmático para un modo de reflexionar nuestra realidad, que a juicio de Kusch configurará hasta nuestros días una estrategia reflexiva para valorar y juzgar distintos aspectos de nuestra vida social ${ }^{3}$. Por ello el tándem conceptual civilización-barbarie que anima dicho trabajo, se transformará en uno de los más determinantes del pensamiento político e institucional durante ese periodo.

La inquietud que lleva a Sarmiento a plantearse esta reflexión, nace por la necesidad de comprender la situación política de Argentina bajo el gobierno de Juan Manuel de Rosas, que a los ojos de sus detractores representa una dictadura tiránica, llena de asesinatos y violencia injustificada. Sin embargo éste no sería el caso de un gobernante déspota llevado por sus propias ansias de sangre y poder, sino más bien $-y$ aquí el giro sarmientino- la manifestación de un modo de ser propio de los habitantes del interior del país.

Esta hipótesis sobre la cual se lleva a cabo el trabajo de Sarmiento, implica una comprensión "genética" de los conflictos argentinos, en donde la cultura autóctona juega un papel capital respecto de la acción política, arriesgando una interpretación del origen y el

2 SARMIENTO, Domingo Faustino. Facundo o Civilización y Barbarie en las Pampas Argentinas (1845), Edición digital, Ed. elaleph.com, 1999.

3 Cf. KUSCH, Rodolfo. Inteligencia y Barbarie (1954), en "Obras Completas". Tomo IV, $1^{\circ}$ Edición, Ed. Fundación Ross, Argentina, 2000. Pág. 237. 
significado del poder, que le dará un resistente punto de apoyo para criticarlo, deconstruirlo y explicitarlo desde sus fuentes cotidianas. Por lo mismo el interés de Sarmiento por la figura del gaucho Facundo Quiroga será paradigmática, pues encarnará plenamente esa manera de ser, ya que constituirá la representación total de un pueblo que se expresa esencialmente a través de su biografía. Rosas sólo será su heredero, su complemento, su perfección, porque lo que en Facundo fue instinto, iniciación y tendencia -afirmará Sarmiento-, en Rosas será sistema, efecto y fin, es decir, el paso de una naturaleza campestre, colonial y bárbara, en arte, política regular y representación ante el mundo ${ }^{4}$.

Sin embargo el análisis de Sarmiento, que en un principio parece animado por este solo elemento, pone en juego una cuestión que será tanto o más determinante, porque si bien el interés por esta indagación se justifica por las urgencias de la época, una lectura más atenta va revelando lo gravitante que es para Sarmiento el hecho de que nuestros pueblos estén en contraste con Europa, es decir, a mi modo de ver en su ensayo no debe leerse únicamente una perspectiva inspirada por comprender dicho proceso histórico y sus eventuales soluciones, sino por la cara externa y la imagen que el conflicto representa "ante el mundo". Por ello no es casual que -a su juicio- un estudio completo que penetrara en la vida política latinoamericana 5 , sólo revelaría el escándalo "ante" el mundo civilizado y no necesariamente las bases para resolver las problemáticas; es más, la misma contraposición nace precisamente desde una preocupación exacerbada por la "imagen" proyectada, por tanto la urgencia de Sarmiento por subsanar la vida política argentina, encontraría su sentido no sólo en dicha problemática política e histórica, sino también y fuertemente en una estética que va en paralelo y silenciosamente determinando dicha reflexión: pasando por los "ojos atónitos" de Europa por nuestra realidad social, hasta los detalles en la decoración de las casas que expresarían dicho carácter civilizado:

\footnotetext{
4 Cf. Facundo, pág. 6.

5 Cf. Facundo, pág. 8.
} 
Da compasión y vergüenza en la República Argentina comparar la colonia alemana o escocesa del sur de Buenos Aires y la villa que se forma al interior: en la primera las casitas son pintadas; el frente de la casa, siempre aseado, adornado con flores y arbustillos graciosos; el amueblado, sencillo, pero completo; la vajilla, de cobre o estaño, reluciente siempre; la cama, con cortinillas graciosas, y los habitantes, en un movimiento continuo. Ordeñando vacas, fabricando mantequilla y quesos, han logrado algunas familias hacer fortunas colosales y retirarse a la ciudad, a gozar de las comodidades ${ }^{6}$.

Respecto de la ropa del hombre de ciudad y el contraste con el hombre del interior:

El hombre de ciudad viste el traje europeo, vive la vida civilizada, tal como la conocemos en todas partes: allí están las leyes, las ideas de progreso, los medios de instrucción, alguna organización municipal, el gobierno regular, etc. Saliendo del recinto de la ciudad, todo cambia de aspecto: el hombre de campo lleva otro traje, que llamaré americano, por ser común a todos los pueblos; sus hábitos de vida son diversos; sus necesidades, peculiares y limitadas; parecen dos sociedades distintas, dos pueblos extraños uno de otro ${ }^{7}$.

Sin duda que asuntos de este tipo y muchos otros de la misma clase son poderosos resortes que motivan su indignación y reflexión, regándose copiosamente en su ensayo y alejándose por mucho del simple dato anecdótico, porque representarían efectivamente una unidad de medida y de expresión paladina de un pueblo civilizado frente a otro bárbaro, como ejemplo mismo de humanidad: la casa pintada, la vajilla, y el traje europeo son el resultado de la ley y el gobierno regular, de la instrucción y del progreso:

La villa nacional es el reverso indigno de esta medalla: niños sucios y cubiertos de harapos viven en una jauría de perros; hombres tendidos por el suelo, en la más completa inacción; el desaseo y la pobreza

Facundo, pág. 28.

Facundo, pág. 30 (subrayado nuestro). 
por todas partes; una mesita y petacas por todo amueblado; ranchos miserables por habitación, y un aspecto general de barbarie y de incuria los hacen notables ${ }^{8}$

El andamiaje que dará sustento a sus afirmaciones será el desenredo de los factores que han envuelto su situación histórica, a partir de una suerte de "arqueología cultural" que dé cuenta de las constantes que determinan un modo de ser; en otras palabras, Sarmiento busca un punto de apoyo que le revele el carácter esencial del pueblo y que le permita a través de él explicar el ejercicio perverso del poder:

Necesítase, empero, para desatar este nudo que no ha podido cortar la espada, estudiar prolijamente las vueltas y revueltas de los hilos que la forman, y buscar en los antecedentes nacionales, en la fisonomía del suelo, en las costumbres y tradiciones populares, los puntos en que están pegados ${ }^{9}$.

La aplicación de su estrategia metodológica se reparte generosamente a través de su ensayo, entregando en cada caso una explicación plausible de cada una de las conductas políticas de Juan Manuel de Rosas. Veré sintéticamente algunos ejemplos.

El primer elemento que Sarmiento nos entrega en su estudio se refiere al aspecto físico de Argentina y los caracteres, hábitos e ideas que engendra esa geografía. En ella describe con grandes visos poéticos la anchura de la pampa, los bosques inmensos, el horizonte incierto, los vastos territorios despoblados, el asedio de los indígenas, de los animales peligrosos, en fin, una seguidilla de elementos hostiles que marcarían el carácter argentino respecto de la muerte:

Esta inseguridad de la vida, que es habitual y permanente en las campañas, imprime, a mi parecer, en el carácter argentino, cierta resignación estoica para la muerte violenta, que hace de ella uno de los percances inseparables de la vida, una manera de morir como cualquier otra, y puede,

\footnotetext{
8 Facundo, pág. 28 (subrayado nuestro).

9 Facundo, pág. 7.
} 
quizá, explicar, en parte, la indiferencia con que dan y reciben la muerte, sin dejar en los que sobreviven impresiones profundas y duraderas ${ }^{10}$.

En esta clave interpretativa la facilidad y liviandad que el paisaje le imprime al hecho de "dar y recibir la muerte", es algo propio del estilo de vida popular, que encuentra su eco en Rosas a través de la sistematización del asesinato y la indolencia institucional ante ella.

Esta tendencia a la complejización de los elementos rudimentarios indica un determinismo y un acto reflejo fruto de los caracteres más duros y primitivos de la población, imposibles de ser sometidos a una autocrítica y menos aún a ser considerados por la misma comunidad como comportamientos cuestionables.

Un segundo elemento que también reposa sobre la base del aspecto geográfico, dice relación con la aglomeración de los ríos y su nula explotación comercial, provocado principalmente por el carácter heredado de los españoles:

El hijo de los aventureros españoles que colonizaron el país, detestan la navegación, y se considera como aprisionado en los estrechos límites del bote o de la lancha ${ }^{11}$.

La irritación de Sarmiento se basa en los ejemplos tomados de Egipto, Holanda o Estados Unidos, que aprovechando los cursos fluviales han sido capaces de fomentar el comercio y consecuentemente los beneficios económicos derivados de aquello, sin embargo el carácter colonial afincado en la población le mantiene en la pobreza y sin posibilidad de alcanzar siquiera algún viso de industrialización, es decir, no está en los "genes" del pueblo la inclinación a profitar de los recursos naturales y sus eventuales ventajas en el comercio nacional e internacional.

Con esto nos acercamos a un punto duro, vergonzoso y que la historia oficial omite en nuestros próceres, porque la idea de la

10 Facundo, pág. 22.

11 Facundo, pág. 23. 
raza y sus desfavorables características congénitas para la vida civilizada, nos pone en medio de un racismo despiadado que se abre a juicios destemplados sobre la humanidad. En el caso de Argentina, y obviamente en todos nuestro países, se dio la fusión de diferentes razas que dieron como fruto lo que hoy día llamamos en sentido amplio "clases populares", que en el caso de Sarmiento merecen los siguientes apelativos:

Por lo demás, de la fusión de estas tres familias [españoles, indígenas y negros] ha resultado un todo homogéneo, que se distingue por su amor a la ociosidad e incapacidad industrial, cuando la educación y las exigencias de una posición social no viene a ponerle espuela y sacarla de su paso habitual. Mucho debe haber contribuido a producir este resultado desgraciado la incorporación de indígenas que hizo la colonización. Las razas americanas viven en la ociosidad, y se muestran incapaces, aun por medio de la compulsión, para dedicarse a un trabajo duro y seguido. Esto sugirió la idea de introducir negros en América, que tan fatales resultados ha producido. Pero no se ha mostrado mejor dotada de acción la raza española, cuando se ha visto en los desiertos americanos abandonada a sus propios instintos ${ }^{12}$.

No encontramos aquí la defensa explícita de una "raza superior" como podríamos esperar en las peores versiones del racismo, pero sí es clara la defensa de una "cultura superior"; lo paradójico es que no viene de la propia cultura aludida, sino desde nuestro punto de vista y el modo en que nos sentimos superados por ella. Lo curioso de esto es que no se basa en una relación bipartita en que una raza desprecia a otra, sino en el autodesprecio y la disociación que intentan los representantes de la civilización a sus propios orígenes.

En este sentido muchos personajes que hoy son honrados como "padres de la patria" porque en su momento pensaron y actuaron en nuestros países en vista de un futuro "mejor", lamentaban fuertemente 
la base étnica de nuestra población, incluso la misma base española, soñando qué hubiese sido de nosotros de haber sido colonizados por ingleses o franceses, tal vez un nuevo Estados Unidos ipero de Sudamérica! Por ello es que se hace común encontrar en la literatura y en acciones políticas concretas, la urgencia por "importar" población europea que sirviera para los propósitos civilizatorios, ya sea poblando territorios desocupados o asimilando sus conocimientos y técnicas en el trabajo industrial: alemanes, ingleses, franceses, italianos, componen el grueso de estos primeros contingentes. Sin olvidar tampoco el deseo inconfesable de "blanquear" y "mejorar" la raza.

A pesar de lo anterior, el punto más álgido de estas ideas se encuentra en el hecho de considerar como fuente indispensable de moralización únicamente a los inmigrantes, haciendo tabla rasa de cualquier elemento positivo que los nativos pudieran aportar. Ellos "importarían" no sólo sus conocimientos y sus hábitos refinados, sino que al mismo tiempo serían la clave para el futuro de los países, inyectando en la mediocre raza autóctona una sangre laboriosa, ejemplo de humanidad, progreso y moralidad, algo muy diferente a lo que dejaba traslucir Facundo Quiroga, la cara visible de todo un pueblo:

Facundo es un tipo de la barbarie primitiva: no conoció sujeción de ningún género; su cólera era de las fieras [...] Dominado por la cólera, mataba a patadas, estrellándoles los sesos a N. por una disputa de juego; arrancaba ambas orejas a su querida porque le pedía, una vez, 30 pesos para celebrar un matrimonio consentido por él; y abría a su hijo Juan la cabeza de un hachazo porque no había forma de hacerlo callar; daba bofetadas, en Tucumán, a una linda señorita a quien ni seducir ni forzar podía. En todos sus actos mostrábase el hombre bestia aún, sin ser por eso estúpido y sin carecer de elevación de miras ${ }^{13}$.

En el frente civilizador, lejos de la "bestialidad", se apostaba a un proyecto que muchas veces se reconocía impulsivo, porque preten-

13 Facundo, pág. 86 (subrayado nuestro). 
día acuñar en pocos años lo que en Europa había costado siglos de evolución, sin embargo no se renunciaba a ello, porque urgía, y se confiaba ciegamente en la dádiva de los dioses que traían consigo los inmigrantes. Un caso concreto, como muchos otros en nuestros países, es el que recuerda Sarmiento en las políticas que llevó a cabo el presidente argentino Bernardino Rivadavia, que bajo su mandato impulsó institucionalmente esta carrera acelerada por el progreso:

Traía sabios europeos para la prensa y las cátedras, colonias para los desiertos, naves para los ríos, interés y libertad para todas las creencias, crédito y Banco Nacional para impulsar la industria; todas las grandes teorías sociales de la época, para moldear su gobierno; la Europa, en fin, vaciarla de golpe en la América, y realizar en diez años la obra que antes necesitara el transcurso de siglos. ¿Era quimérico este proyecto? Protesto que no ${ }^{14}$.

El carácter de futuro que adquiere el ideal de civilización, supone una base social, cultural y racial inapropiada para el proyecto, entonces se hacía imperativo forzar el proceso y crear las bases necesarias para su consolidación en el tiempo. El problema consistía en cómo sumergir a una inmensa masa de "salvajes" a este nuevo ser, hacer y saber que en Europa obviamente había tomado un proceso histórico tremendamente complejo, resultado de una conjugación de factores imposibles de reproducir artificialmente en un contexto tan diferente como el nuestro. Sin embargo las mismas ideas importadas contenían la clave de su reproducción, dando lugar a una fe prácticamente infinita en la educación, que desembocó en la constitución de las primeras universidades nacionales y el comienzo de la instrucción pública. El mismo Sarmiento es un reconocido promotor de la educación primaria en Chile y Argentina, pero con una concepción de la educación que no se basa en la promoción y reproducción de la cultura propia, sino en el poder transformador que ella posee; no se trataba simplemente de enseñar a leer y escribir, sino de asimilar

14 Facundo, pág. 113 (subrayado nuestro). 
una cultura diferente, una tradición diferente, haciendo caso omiso del enorme bagaje cultural previo.

El problema de aquello es el punto de partida, es decir, a partir de dónde comenzaría la implementación de este proyecto, porque negando de plano cualquier posible integración del barbarismo autóctono, se enfrentaban a una población que debía ser formada a partir de una materia absolutamente informe, sin nada que aportar, sin posibilidad de vincular con su realidad las novedades traídas del mundo civilizado:

Pero aun en el caso de seguir el movimiento, mucho tiempo y dinero costaría a los gobiernos sudamericanos el intento de crearse, cada uno de por sí, sistemas y métodos de los que no se encuentran antecedentes ni en la historia, ni en las instituciones de aquellos países ${ }^{15}$.

Por lo mismo:

Para formar una fuerte opinión en América que se convierta en hechos y leyes, he aquí el tema que las necesidades y tendencias del siglo suministran: escuelas, libros, agricultura inteligente ${ }^{16}$

En este marco no cabe la posibilidad de una crítica capaz de adaptar a la realidad latinoamericana las tendencias y necesidades que su tiempo suministraba para la superación de las naciones; no había tiempo, dinero ni antecedentes al respecto; por ello se valida doblemente la copia flagrante de los modelos importados, porque contendrían en sí mismos la garantía de su éxito por el hecho de venir de países modelos, y al mismo tiempo porque constituyen un sucedáneo inmediato a la realidad autóctona, obteniendo rápidamente un lugar en la historia universal que no cuestiona tradiciones, culturas y realidades. Recordemos un par de afirmaciones de Sarmiento a propósito de la destrucción institucional provocada por Rosas:

15 SARMIENTO, Domingo Faustino. Ambas Américas; Revista de Educación, Bibliografía y Agricultura, Edición digital, Editor Domingo Faustino Sarmiento, New York, 1867. Introducción.

16 Ídem. 
[...] mi ánimo es sólo mostrar el nuevo orden de instituciones que suplantan a las que estamos copiando de Europa $[\ldots]^{17}$.

O respecto de la moda:

A la par de la destrucción de las instituciones que nos esforzamos por todas partes en copiar a la Europa, iba la persecución al frac, a la moda, a las patillas, a los peales del calzón, a la forma del cuello del chaleco y el peinado que traía el figurín; y a estas exterioridades europeas se sustituía el pantalón ancho y suelto, el chaleco colorado, la chaqueta corta, el poncho, como trajes nacionales, eminentemente americanos $[\ldots]^{18}$.

La mención marginal que se hace al distinguir las "exterioridades" europeas de elementos que podríamos considerar, en oposición, como elementos "internos", nos brinda la posibilidad de hallar dos niveles en el proceso civilizatorio. Por una parte un nivel interior que se vincula con la institucionalidad, y otro exterior que se vincula con el aspecto. Los dos van de la mano, pero Sarmiento simplifica la relación, porque le bastaba con la manifestación de la exterioridad para creer asegurada la asimilación profunda de una institucionalidad, por ello también se esforzaron en hacer ver a nuestras ciudades como fieles reflejos de Europa, a levantar universidades con una orgánica que "persigue" el saber europeo, a implementar un currículum similar al que se usaba con los niños norteamericanos, a vestirse a la usanza de los señores europeos, etc., porque se trataba precisamente de levantar una gran cortina de humo -usando la expresión de Kusch- para no sentirnos ni que nos vieran en nuestra realidad; un gran montaje rápido y barato que no pide historia. Mientras tanto el nivel interno, aquellos resortes institucionales que están llamados a dar forma a una vida, se mantendrán ignorantes y alejados precisamente de la interioridad del pueblo, constituyéndose también en parte de la escenografía, con la diferencia

17 Facundo, pág. 221 (subrayado nuestro).

18 Facundo, pág. 237 (subrayado nuestro). 
que serán el telón de fondo sobre el cual caminarán los ciudadanos vestidos decentemente: un hombre con traje sólo podrá caminar en dirección a un lugar que vaya con el traje, ya sea un banco, el correo, el teatro, en fin, todo lo que pudiera emular de manera óptima la vida en las grandes metrópolis ${ }^{19}$.

La interpretación que hemos hecho de este trabajo arquetípico del siglo XIX no implica que la nomenclatura y la intencionalidad de la reflexión sea exclusiva de la obra de Sarmiento, por el contrario, las referencias a la civilización y la barbarie no sólo se encuentran en su trabajo, sino que también es posible encontrarlas en el mismo tono y con el mismo vocabulario en otros intelectuales de la época, por ejemplo en el chileno Francisco Bilbao, lo cual nos muestra claramente que estamos ante un frente de crítica y debate mucho más complejo y amplio respecto a las ideas que han fundado nuestras naciones. Revisemos algunas ideas del chileno que nos sirvan de complemento ${ }^{20}$.

En 1844, un año antes de la publicación de Facundo, Bilbao escribe su famoso y polémico ensayo titulado Sociabilidad Chilena ${ }^{21}$, en el cual critica lo que él considera el representante de la edad media en Chile, a saber, España, teniendo como inspiración a la Iglesia Católica y como estructura social el feudalismo:

19 El caso de la ciudad de Santiago es arquetípico, porque durante el periodo de Benjamín Vicuña Mackenna, intendente de la ciudad entre 1872 y 1875, se llevó a cabo un gran proyecto de transformación para hacer de la capital de Chile el "París Americano". Sus escritos de la época dejan claro testimonio de sus intenciones "civilizadoras", por ejemplo La Transformación de Santiago (1972), Moralidad Pública de Santiago (1972), Bando acerca del Asco de las Calles (1873), y especialmente Un año en la intendencia de Santiago; lo que es la capital y lo que debería ser (1873) y El Paseo de Santa Lucía (1872). Al respecto el trabajo historiográfico Génesis de la Transformación de Santiago (2000) de Leslie Wehner es muy ilustrativo.

20 Es justo señalar también que aquí hago mención al primer Bilbao, antes de su decepción de Francia y Europa. Al respecto realicé una conferencia titulada El Itinerario del Pensamiento de Francisco Bilbao como "Parábola de Ajuste" para el Pensamiento Filosófico Chileno del Siglo XXI; La Reconfiguración de la Historicidad Latinoamericana, en la Jornada de Filosofía Chilena 2013 realizada en el Museo Benjamín Vicuña Mackenna, Santiago de Chile, el 23 de agosto de 2013.

21 BILBAO, Francisco. Sociabilidad Chilena (1844), en "Francisco Bilbao; el Autor y su Obra", 1 Edición, Editor José Alberto Bravo, Ed. Cuarto Nuevo, Chile, 2007. 
Nuestro pasado es España. La España es la edad media. La edad media se componía en alma y cuerpo del catolicismo y de la feudalidad ${ }^{22}$

Por lo mismo se hace necesario romper con ese pasado y abrirse a la modernidad:

Nuestra revolución es la mudanza violenta de la organización y síntesis pasada para reemplazarla con la síntesis vaga pero verdadera que elabora la filosofía moderna ${ }^{23}$.

A juicio de Bilbao, en Chile la revolución independentista se manifestó en dos bloques, por una parte una revolución reflexiva y crítica del pasado, propia de la minoría educada, y por otra parte una revolución espontánea, la del pueblo, que se siente entusiasmado con las nuevas libertades y la exaltación política. La primera pudo sobrevivir sin nuevas creencias, contando únicamente con la certidumbre de la libertad futura y la crítica al pasado, pero la segunda no, porque no veía en la libertad política sino un hecho aislado, separado de la inmensa complejidad del proceso, por ello es que "el pueblo quedó antiguo" ${ }^{24}$, porque no fue capaz de cerrar el ciclo, fue ciego a la historia y a los derechos ganados. Por lo mismo los nuevos gobernantes, conservadores por definición, sólo pudieron llenar el vacío con el mismo pasado, es decir con un despotismo constitucional símil del feudalismo y un fomento nuevo del catolicismo, reflejo absoluto de la impotencia para reorganizar la sociedad basada en las nuevas ideas:

O salimos de la revolución o no. Si salimos de ella, nuestro deber es completarla. Si no, nuestro deber es definir lo que somos y cuál es nuestra tradición como nación ${ }^{25}$.

Esta disyuntiva se resuelve negativamente, porque a pesar de los esfuerzos por consolidar la revolución, los antiguos privilegiados, aquellos que sin-

22 Sociabilidad Chilena, pág. 154 a.

23 Sociabilidad Chilena, pág. 163 b (subrayado nuestro).

24 Sociabilidad Chilena, pág. 164 b.

25 Sociabilidad Chilena, pág. 165 b. 
tieron tocado su orgullo y que no resistieron el nacimiento de un nuevo orden social basado en ideas nuevas que proclamaban a la libertad, la igualdad y la fraternidad como leyes universales, reaccionaron como lo que son, el pasado, es decir, como "el elemento indígena español que no puede resistir en su orgullo la innovación de creencias, de formas de gobierno, de costumbres liberales en la esfera pública y privada"26, justificando su acción violenta y conservadora en un simple silogismo:

La educación invadía a las creencias españolas. La autoridad favorecía la invasión. Luego destruyamos esa autoridad ${ }^{27}$.

Si ésa es la realidad histórica que vive Bilbao, entonces la disyuntiva se resuelve por definir el ser chileno y las tradiciones como nación que impiden completar la revolución. En este punto la coincidencia estratégico-metodológica con Sarmiento es notable, porque nuevamente será el arraigo y el carácter que da la tierra, la justificación última de un modo de ser que contrasta con la civilización.

Para Bilbao el uso del caballo en el pastoreo, la caza y las aventuras viene a ser un factor clave en todos los pueblos, que en el caso del chileno son asumidas por su personaje típico, el "Huaso":

El huaso, que resume las cualidades que notamos, tiene, por cierto, su carácter más peculiar, más original y más salvaje en los lugares que favorezcan por sus pastos y guaridas las crías de ganados. En Chile el sur es más extenso, más regado, de mejores tierras para el pasto y de mejor clima para el hombre y el animal. Es frío y excita a la actividad; montañoso y acostumbra a la constancia, a la separación y, últimamente, al desarrollo físico del pecho ${ }^{28}$.

Y continúa:

Estas influencias de la localidad producen resultados morales. El huaso corriendo por la cima de los montes respira la independencia en su

26 Sociabilidad Chilena, pág. 167 b.

27 Ídem.

28 Sociabilidad Chilena, pag. 168 a (negrita en el original). 
carrera. El huaso sepultado entre los montes se encuentra separado de la comunicación moral; es solitario, selvático [...] Las creencias de nuestros huasos son católicas y españolas [...]; no pueden, por la vida que llevan, presenciar espectáculos distintos, deben tener un completo desarrollo, de aislamiento, de barbarie y conservación ${ }^{29}$.

Ahora Bilbao, en el mismo tono que Sarmiento, afirmará a propósito del enfrentamiento bélico entre liberales y conservadores chilenos en la batalla de Lircay de 1829:

Esos hombres son los que han bajado de las montañas y llanos del sur a la voz de los que exaltaron su fanatismo y les prometieron saqueo. ¡Helos allí! Ved en acción el espíritu selvático, el espíritu rencoroso del ignorante y salvaje a lo que es nuevo y civilizado ${ }^{30}$.

Las palabras de Bilbao hablan por sí solas, y prácticamente se explican de la misma manera que las de Sarmiento, pues responden al mismo cuadro conceptual que compartían muchos de nuestros pensadores fundacionales. Así lo expresa la profesora Clara Jalif cuando señala que en Bilbao se encierran las claves culturales de toda una época, siendo el eje civilización-barbarie un juego categorial de oposiciones que define las ideas sobre las nuevas naciones en su pasado, presente y futuro, derivándose de ello todo un abanico de conceptos como instrumental de análisis y crítica social, por ejemplo los binomios luces-ignorancia, república-monarquía, pueblo-rebaño, independencia-dependencia, emancipación-opresión, etc:

Todo discurso se articula en torno a oposiciones simbólicas que pueden ser denominadas categorías histórico-sociales, dotadas de una carga valorativa. Las mismas permiten descubrir la presencia de un juego de reconocimientos y rechazos respecto de la heterogeneidad social. Las categorías poseen, entonces, una función epistemológica de organización de los campos semánticos de un corpus dado, y una función axiológica de transmisión e imposición de convicciones 
relativas al deber ser, por lo cual cumplen un papel de regulación y orientación de la praxis ${ }^{31}$.

Estas observaciones que comparto plenamente con la profesora Jalif, son precisamente las principales consecuencias de esa visión dicotómica de la realidad, pues determinan el ámbito epistemológico respecto al modo de comprender la realidad de su tiempo y su carácter impositivo sobre el deber ser, tiñendo con un cierto tipo de valores específicos una discusión que debería incluir en esencia a todos los actores sociales.

Bilbao y Sarmiento aborrecen a la población indígena, negra y criolla como si de antemano fuesen sociedades caóticas, sin estructura determinada y pobres representantes de la humanidad, todos sin posibilidad alguna de ocupar un lugar en el mundo, es decir, nuestro pensadores no pueden salir del rígido marco conceptual que ellos mismos han levantado, porque han instaurado un discurso hegemónico y totalizante en las bases mismas de su pensamiento, teniendo como única posibilidad real de sociedad, un ideal de vida "europea" que la misma historia se ha encargado de contradecir, sobre todo por las embestidas imperialistas de su amada Francia, de la cual ambos fueron testigos y de la cual Bilbao, a mi modo de ver, saca las verdaderas consecuencias.

\section{El Drama Mestizo}

En lo que he revisado nos encontramos con una visión respecto del futuro de nuestras naciones que se basa en la copia de los modelos civilizatorios: los ejemplos que he tomado de Sarmiento y Bilbao sólo son una muestra significativa de esta manera de pensar. Sin embargo no es sólo un gran proyecto que engloba las más variadas actividades humanas, sino también una rígida concepción de la historia de nuestros pueblos que subrepticiamente alimenta ese ánimo.

31 JALIF, Clara. Francisco Bilbao y la Propuesta Libertaria de América, $1^{\circ}$ Edición, Ed. Universidad Nacional de Cuyo, Mendoza, 2003. pág. 44. 
He pretendido mostrar en las palabras de Sarmiento su visión racista de la cultura latinoamericana, dando lugar a una idea de superioridad cultural que debe a toda costa ser implantada en nuestras sociedades, incluso injertando directamente la sangre de esos pueblos: las políticas migratorias para captar población de origen europeo son parte estratégica de esta visión. Por lo mismo nos encontramos con una concepción del pasado, del presente y del futuro que si bien no cuaja explícitamente en una gran filosofía de la historia, al menos nos sitúa ad portas de concebirla como un factor gravitante en nuestros proyectos nacionales.

El binomio civilización-barbarie reviste una dialéctica compleja y cerrada de innumerables tensiones sociales, tan variadas que van desde el sistema educativo hasta la decoración de las casas, sin embargo no son temáticas puntuales que giren sobre sí mismas de manera autónoma, sino más bien responden a una lógica histórica que dista por mucho de las versiones oficiales.

Cuando se plantea la cuestión en términos disyuntivos, es decir, "ser o no ser salvaje ${ }^{\prime 32}$, nos topamos con una escisión radical entre el pasado y el futuro, el primero bárbaro y el segundo civilizado. Esto significa que el pasado bárbaro pierde toda relación de continuidad histórica con la civilización y al mismo tiempo ésta pierde toda relación de continuidad histórica con la barbarie, es decir, se transforman en dos átomos ciegos el uno del otro, como dos conjuntos cerrados, el primero cercado hacia adelante por su ausencia de futuro y el segundo cercado hacia atrás por su ausencia de pasado. Al primero se le niega toda proyección, al segundo se le niega todo origen, generando una especie de limbo histórico, un punto medio en el cual se cierra absolutamente el pasado y se abre absolutamente el futuro. Esta discontinuidad genera una versión sui generis de los procesos históricos, que da lugar a una valoración ilimitada del porvenir como un fin en sí mismo: el ensueño de ser un día como un país europeo sin la más mínima atención a la realidad subyacente se transforma 
en una cuestión viable, en una posibilidad real, porque en sí misma encierra la desvinculación.

Lo paradójico es que asumiendo las ideas de progreso, se hace una interpretación heterodoxa de la ley histórica que defiende el positivismo, porque no se asume como un proceso necesario y gradual, en el cual se van superando sucesivamente los estadios anteriores; más bien hay una imposición violenta que promueve la negación y destrucción del estado anterior en una lucha declarada contra él, transformando a la barbarie en una "anomalía" que debe ser remediada cuanto antes para entrar en la historia universal y su proceso "normal".

De aquello se desprenden dos vectores, uno que corresponde a nuestra realidad que debe ser remediada y otro que corresponde a la "verdadera" historia de la humanidad. Con esto aparece un abajo histórico como versión bastarda y apocada de nuestra realidad incómoda, aquella que abunda en el interior de nuestro países y en las capas más profundas de nuestras sociedades, constituyéndose en un lastre para "saltar" al torrente de la verdadera historia, aquella que protagonizan sólo algunos pueblos escogidos por el destino. Por lo mismo aparece un arriba histórico, un lugar que jerárquicamente representa lo mejor de la humanidad, su manifestación más plena, como Grecia, Roma, Francia, Inglaterra, Alemania, Estados Unidos, todos canalizados en la misma línea temporal, y mientras tanto nosotros esperamos impacientes un lugar que nos permita ser miembros de este club de realidad, intentando deshacernos de todo aquello que nos lo impide, viviendo en silencio nuestra poca valía histórica, y alimentando una atracción que se nos muestra como la única posibilidad real de ser nación, pero que sólo incrementa nuestro resentimiento y el deseo de negarnos. Es el hombre que cierra sus ojos para imaginar un país hermoso, limpio y ordenado, con instituciones a la altura de los tiempos, presentable ante el mundo, pero que al abrirlos encuentra que su gente no es la adecuada, porque son demasiado primitivos, rústicos, aman la libertad que les da el caballo, aborrecen los ríos, buscan la soledad, son flojos, ladrones, feos, en definitiva no son una raza bien dotada para los tiempos, carecen de la virtud republicana -dirá Diego Portales unos años antes-, por eso viene al caso preguntarse: ¿Con qué pueblo 
están llenando sus sueños? ¿Quiénes son en definitiva los habitantes imaginarios de sus ciudades?

Ante estos hechos la "construcción" o "levantamiento" de la civilización parte como una evasión de la realidad, por eso se hace suficiente construir un edificio que albergue alguna institución importada, o basta con pintar las casas, o vestirse de una manera determinada, porque lo importante es lograr el aspecto de... para que "ante los ojos" de Europa nuestra verdad no se constituya en un escándalo. Por lo mismo el pasado debe mantenerse así, de lo contrario desmorona el montaje, porque viene a ser la revelación de su origen, el recuerdo de su artificialidad, porque se descubriría en su pretensión evasora. Esta mecánica del encubrimiento garantiza su éxito, porque es el maquillaje necesario para lograr el aspecto deseado, sin embargo no es más que una cosmética, porque la vida ha seguido su curso más allá del frac y la ciudad, depositada y olvidada en esa línea histórica de "abajo", pero real y constante. Por este motivo Kusch cree que es urgente retomar la vida del pueblo, sacarla de este "escenario" y captarla en su manifestación cotidiana, introducirse en ella y comprender la verdad escindida de su "aquí y ahora".

En este punto de reflexión la filosofía de Kusch no puede identificarse sin más con una fenomenología, porque no le interesan las estructuras a priori de esa existencia, sino revelar y comprender su drama, es decir, su copertenencia a una estructura social pensada desde una inteligencia ciudadana, y esa otra parte de sí que sobrevive desde un pasado que en apariencia ha quedado absolutamente atrás. La intención kuschiana de encontrarse con esa verdad dual es finalmente la intención de encontrarse con el drama del mestizaje mental, la misma tensión entre la civilización y la barbarie que no se ha resuelto, manteniéndose en el tiempo dividiéndonos y truncándonos sin posibilidad de optar definitivamente por ninguna de ellas: ni absolutamente civilizados ni absolutamente salvajes. Sin embargo el camino no estaría en insistir en la aniquilación del contrario, sino en la observación atenta de su verdad, de su participación efectiva en la realidad de nuestras sociedades, en visibilizar esa barbarie como 
un elemento gravitante y positivo de nuestra manera de habitar en el mundo. En este sentido Kusch mantiene el punto de vista estético que de uno u otro modo ha caracterizado a nuestros pensadores, constituyéndose en un seguidor de esta "tradición" a través de lo que se llamará la seducción de la barbarie, porque le permite internarse en ella, comprenderla y juzgarla, más allá del prejuicio inspirado por la seducción de la civilización.

La primera reflexión de largo alcance sobre este fenómeno comienza con una escena cotidiana ${ }^{33}$ : la experiencia porteña de estar acodado en la mesa de un café, contemplando el paso de la gente a través del ventanal. Kusch se interesa en un momento como ése, porque muestra de manera absoluta el aquí y ahora en la ciudad: es la vida de cualquiera, sin trascendencia histórica ni biográfica, pero íntima, una especie de vacío en nuestras ocupaciones en el que podemos salirnos, descansar y meditar un poco sobre nuestros quehaceres. Kusch escenifica en ese café el momento de la reflexión, la sensación de esa persona respecto de lo que pasa a su alrededor; esto significa la toma de conciencia de nuestra vida en la ciudad, pero al mismo tiempo la revelación de un abismo entre aquél que toma su café y el transeúnte anónimo que pasa por la ventana, porque la ciudad nos une como partes de un todo inteligente, pero que escapa a los niveles más profundos de nuestra existencia.

Vivimos nuestras ciudades como un tejido, en donde cada cosa tiene su lugar, su sentido, su razón de ser, pero esto no es capaz de entregar una respuesta al sentido de nuestra existencia, porque todo ha quedado atrapado en un reino de intereses estructurados, que flotan por sobre la vida particular, omitiendo, negando y forzando a la clandestinidad nuestras inquietudes íntimas; en cambio, nos sitúa dentro de un gran interés colectivo que aparenta conectar con el elemento vital de la comunidad: pero algo acusa la falta de ese nexo, la expresión de esa verdad cotidiana.

$33 \mathrm{KUSCH}$, Rodolfo. Seducción de la Barbarie: Análisis Herético de un Continente Mestizo (1953), en "Obras Completas", Tomo I, 1Edición, Ed. Fundación Ross, Argentina, 2000. Pág. 17. 
Si a partir de este criterio buscamos la relación entre el hombre del café y el transeúnte, encontraremos cifras, productos, trabajadores, máquinas, comercio, en fin, la persona se transforma en un átomo dentro de la totalidad del tejido ciudadano, provocando una antinomia que según Kusch nos impide acercarnos al transeúnte anónimo y lograr con él un contacto verdaderamente humano y comunitario, porque a fin de cuentas únicamente somos ciudadanos, es decir, una parte ínfima de una gran construcción racional que nos ofrece sentidos y explicaciones abstractas, que nada aportan al significado real de mi existencia y mi vinculación con los otros: es la ciudad la que crea el abismo, la que consume a la existencia en cifras y no la consumar en vida.

Sin embargo Kusch apuesta que a cada instante se perturba ese tejido racional, ya sea en la borrachera de un empleado de banco, en la patota que grita a mitad de la noche, en la fiesta popular, en el tumulto, en el bar, en el fútbol, en el Café, en la letra romántica de algún cantante popular, en la brujería, en la mitología viva, en las ferias populares, o simplemente al bailar un Tango, el ejemplo predilecto de Kusch.

Esa "razón" que debería atenderse todo el tiempo, muestra precisamente la falsedad, la pretensión, porque son una fuga, un lapsus que hiere a esa racionalidad. Por ello vivimos dos verdades, una que se impone por la ciudad y otra que vivimos hondamente, pero que nos cuesta percibir, por eso el conflicto, la tensión, la crisis, porque nos dejamos arrastrar por esa verdad citadina, pero no hallamos un sentido pleno en medio de las calles y edificios que entronque radicalmente con el nuestro. Por lo mismo no estamos ante un nihilismo declarado, sino ante la "sospecha" de esa falsedad, aquella provocada por la verdad latente que compartimos con el hombre del café al sentirse movilizado para consumir su vida en un gran mecanismo inteligente, que demasiadas veces sólo es el ideal y la conveniencia de unos pocos. Nuestro personaje es ciudadano en el pleno sentido de la palabra, vive y convive en la ciudad, pero al mismo tiempo siente ese velo de artificialidad, porque algo quedó atrás, algo de él no está puesto en las calles, su ser no está en las construcciones, en las instituciones, en las medidas gubernamentales que se toman a imagen de los países 
"desarrollados", pero tampoco hay una resolución, la balanza no se inclina ni por la plena barbarie ni por la plena civilización, de ahí la tensa convivencia entre estas dos verdades, porque esto es para Kusch la esencia del mestizaje y su drama, es decir, la escisión que permanece en el ciudadano, aquella que por una parte falsea a la ciudad y por la otra lo aleja de sus orígenes ${ }^{34}$.

La ciudad representa el paso de las tinieblas a la luz, de la inconsciencia a la consciencia, del caos al orden, de lo feo a la bello, es decir, de la barbarie a la civilización. Ella está llena de fines y utilidades, nos sume en un trajín infinito y agotador de metas colectivas que nadie tiene tan claras, porque son borrosas, pero justificadas, la "síntesis vaga pero verdadera" ${ }^{35}$ que defendía Francisco Bilbao, porque todos "sabemos" que es para mejor, para superarnos, para ser verdaderos países, pero no sabemos bien de qué trata, por ello se suspende la pregunta por el sentido de esa acción colectiva, delegando la respuesta en algo indeterminado que nos permita cómodamente "hipotecar la verdad más íntima, en razón de alguna utilidad"36 que en el fondo nos es ajena y lejana. Aquí no hallamos el paso entre una manera de habitary la inteligencia que debería depurarse en leyes e instituciones, sino la sumisión de la existencia a una inteligencia funcional, a unas razones importadas que se hacen valer por sí mismas, depurándose en "[Los] archivos, en los papeles, en las oficinas, en el dominio de las leyes y de las normas policiales, en la justicia civil, en la educación, y alcanzando su poderío en el Estado" ${ }^{37}$, es decir, su máxima expresión.

Ante esta situación no queda más que la ironía, la broma, la ambivalencia, el descrédito que de alguna manera envuelve todas nuestras iniciativas, porque al no resolvernos optamos por la medianía, un punto cómodo que nos facilita la copertenencia, porque el hombre que vive así se queda "en el factor común de la realidad que lo rodea"38, ahí depo-

34 Cf. La Seducción de la Barbarie, pág. 46.

35 Cf. Cita 22.

36 La Seducción de la Barbarie, pág. 49.

37 La Seducción de la Barbarie, pág. 50.

38 ídem. 
sita su fe en aquello ya establecido, en lo que no complica demasiado, porque a pesar de todo cree en esa unidad inteligible que mantiene a la sociedad, dejándose seducir no por su propia barbarie, sino por la simplificación que la ciudad le otorga a su vida, porque le sirven para mantenerse irresoluto, cómodo y confiado en su mediocridad. El intelectual, por su parte, el que se supone encargado de "pensar" estas cosas, tampoco las advierte, y si lo hace no tiene las fuerzas suficientes "para alcanzar el ser que presiente" ${ }^{39}$, porque también opta por la medianía, ignorando el reverso social, quedándose en sus juegos académicos, revolviendo el mismo discurso descontextualizado para sentirse parte de algo importante, pero que a fin de cuentas no es más que el miedo de enfrentarse a su propia realidad, aquella que le enrostrará su inutilidad y la soledad que implica abandonar todo apoyo conceptual foráneo.

Hoy día no hablamos de civilización-barbarie porque parece una discusión antigua, precisamente superada por el triunfo de la ciudad; así lo muestran el nombre de nuestras instituciones, la apariencia de nuestras calles, lo que aprenden los niños en la escuela, porque se ha ocultado el problema mismo, es parte de su mecánica no mostrarse tal cual, pero sofisticado y otra vez recubierto de un valor en sí, aparece renovado y omnipresente como desarrollo-subdesarrollo. Aquí no se presenta explícitamente una denominación con carga moral y racial, sin embargo no se abandona la idea de inferioridad y superioridad, de una historia propia de país subdesarrollado y otra propia de país desarrollado, luminosa, perfecta, protagónica: ahora no nos quedamos en la barbarie que está "abajo", ahora nos quedamos en el sub-desarrollo.

Al momento que Kusch discute el concepto de desarrollo ${ }^{40}$ que tanto se impone en nuestros países como centro de gravedad en la discusión económica, cultural, social, política, etc, su intención es descubrir en el presente la manifestación de este enfoque y la intención de su sentido, que omite a la cultura ya arraigada suponiéndola sin ningún tipo de anclaje simbólico y dispuesta como tabla rasa a cualquier nueva

39 La Seducción de la Barbarie, pág. 52.

40 KUSCH, Rodolfo. Geocultura del Hombre Americano (1975), en "Obras Completas" Tomo III, $1^{\circ}$ Edición, Ed. Fundación Ross, Argentina, 2000. Pág. 112 y ss. 
intencionalidad; dicho de otra manera, hay una concepción implícita de la cultura que la muestra en su mínima expresión y tan solo como sujeto pasivo y modificable.

En principio la etimología de la palabra castellana nos orienta claramente respecto de su significado -y Kusch parte de aquello-, pues aparece en ella un elemento contenido, aquello "arrollado" que se "des"-arrolla, es decir, se parte de un estado de cosas para llegar a otro y así llevar a plena manifestación lo contenido en el momento primero: si hablamos de una planta -siguiendo el ejemplo de Kusch-, entendemos que al desarrollarse alcanza un estado que se basa en los momentos previos, es decir, hay una continuidad natural, biológica, un plan, un código, que permite alcanzar el estado de desarrollo como un proceso autónomo, que lleva en sí mismo el germen de su plena manifestación. Sin embargo las castas gobernantes han pretendido forzar el proceso, acelerarlo, pero ni siquiera en el sentido de lo "arrollado" que se despliega, sino que lo han comprendido desde un punto de vista externo, es decir, no es ese elemento contenido el que preocupa des-arrollar, sino que bajo la constatación negativa de ese punto de partida, el proceso implica mutar desde fuera el movimiento intrínseco, para que éste no llegue al punto de despliegue que originalmente contenía y arribe a uno arbitrariamente escogido.

Si ahora ponemos esto en los términos que Kusch nos plantea, la barbarie se muestra como el punto de partida negativo que no debe llegar a consolidarse, por tanto hay que hacer todos los esfuerzos necesarios para modificar esa naturaleza salvaje y mutarla a una naturaleza civilizada, pero no porque hayan elementos intrínsecos que deban ser des-arrollados en ese sentido, sino que con base en el anhelo de ser como, el proceso será orientado por elementos absolutamente extrínsecos al punto de partida, es decir, a un modo de Ser, a una manera de habitar, a una cultura, a una sociedad, a una manera de organizarse, a unas costumbres; en otras palabras, a una existencia que se ha configurado a su propio ritmo y necesidades ${ }^{41}$.

41 Cf. Geocultura del Hombre Americano, pág. 113. 
Sin embargo no basta con una reflexión teórica en torno a la tensión semántica en la manera de comprender este concepto, ya sea en sentido interno o externo, porque lo más importante es la consecuencia ética de esta tensión. Cuando hablamos de un desarrollo autónomo regido por la legalidad propia de lo "arrollado", nosotros estamos pensando en un Ethos determinado y sus posibilidades de despliegue, es decir, estamos con una mirada no sólo comprensiva en el sentido de posicionarnos dentro del proceso mismo y abrirnos a la lógica existencial que allí se juega ${ }^{42}$, sino al mismo tiempo y como parte integral de la comprensión, el respeto y promoción de su manifestación y des-arrollo. En el caso de la comprensión externa, que en sentido estricto no es más que una mirada negativa que no tiene posibilidad ni ánimo de implicación alguna con el Ethos, se da precisamente el movimiento contrario, es decir, no hay ningún tipo de respeto ni promoción, constituyéndose en violencia radical, porque se niega una existencia en sentido ontológico, castrando el derecho a participar activamente en su propia organización social, a tener una historia auténtica y finalmente un lugar propio en el mundo.

En la propuesta fenomenológica de $\mathrm{Kusch}^{43}$ la existencia se proyecta en sus posibilidades en la medida que tiene una intuición existencial de alcanzar su realización, es decir, su totalidad, porque sobre la base de este anticipo de sí misma es que el proyecto tiene sentido en cuanto proyecto. Este axioma existencial es la verdad primera, por tanto nos encontraríamos con el deber vital de buscar ese sentido y responder a este impulso que en sí mismo contenemos: la proyección implica esta exigencia. Sin embargo no es un arrojo ciego hacia la nada, sino

$42 \mathrm{KUSCH}$, Rodolfo. Una Lógica de la Negación para Comprender a América, en "Obras Completas", Tomo II, $1^{\circ}$ Edición, Ed. Fundación Ross, Argentina, 2000. Cf. Pág. 555. En este trabajo Kusch reflexiona sobre la comprensión a partir de la necesidad de salir de una lógica de conocimiento que no surge de los problema mismos de Latinoamérica, sino de modelos importados que responden a dinámicas conceptuales diferentes; por lo mismo la comprensión será entendida a partir de dicho conflicto epistemológico y definida negativamente como la absorción, el condicionamiento y el sacrificio de esa racionalidad ante el sujeto comprendido.

43 Cf. Una Lógica de la Negación para Comprender a América, especialmente pág. 551 y 552 . 
que se arropa de manera previa con un bagaje cultural y un margen de pertenencia que determina la proyección, es decir, la existencia está anticipada por la cultura en que se proyecta. Por lo mismo, ese proyecto alcanza sentido y validez dentro de las posibilidades simbólicas que se le abren bajo el horizonte cultural previo, de ahí el sinsentido de algunas actividades humanas desde el punto de vista foráneo, pues carecen del horizonte simbólico que les permite captar el significado de aquellas actividades o labores. De esto se desprende una innumerable variedad de proyecciones posibles que dependen exclusivamente del código cultural que les da sentido, o bien de la mirada comprensiva de aquel que pretende acercarse a ellas como posibilidades viables, sin tener necesariamente en la mano la clave hermenéutica que le abra el misterio, por ello que la comprensión al mismo tiempo tiene una carga ética, y al contrario, ignorar las posibilidades dentro de cada cultura es negar y negarse a reconocerla como tal en su validez y verdad.

El desarrollo que se entiende como un llegar-a-ser-otro-diferente, lo que hace es negar las proyecciones de una existencia y la cultura completa que está detrás de ella, por eso es que los intentos permanentes que de manera general comprendemos bajo el concepto "civilización", se muestran como persecución y destrucción vital de un pueblo a través de la mutación sistematizada y racionalizada de su Ethos, es decir, de su domicilio existencial, de su lugar en el mundo, de su manera de presentarse ante sí mismo y frente a los otros, vistiendo los discursos oficiales bajo el imperativo tautológico y acrítico del progreso y el desarrollo ad infinitum. Por lo mismo, la consecuencia directa para la existencia es una desorientación radical, pues la proyección no sólo alcanza su sentido dentro de una cultura, sino que al mismo tiempo es una manera de enfrentar la vida, es decir, se constituye en una estrategia ${ }^{44}$ que nos permite habitar a través de una sabiduría heredada, ya sea en sentido artístico, erótico, religioso, político, económico, etc., que cada cultura ha sabido acumular y llevar adelante logrando los ajustes necesarios para su propia 
supervivencia y evolución. Sin embargo al imponer un modo de vida único, que llamamos civilización, y ahora desarrollo, de alguna manera estamos no sólo negándola, sino también subestimándola en cuanto posibilidad cultural, política y social viable, haciendo de la humanidad un foco unívoco que en su misma esencia niega la posibilidad de encontrarla de una manera diferente, conformando una escala de valores absoluta que valida las acciones humanas dependiendo de la cercanía o alejamiento a su centro de gravedad: la civilización y todo lo que conlleva se afirma tautológicamente, autoconvenciéndose de la necesidad de transportarse a todos los rincones de la tierra como un bien en sí.

En este drama mestizo, es decir, en la escisión generada por ideas casi esquizofrénicas que componen nuestra estructura y dinámica social, Kusch concentrará sus esfuerzos por hallar un punto de contacto que logre la integración de lo que Sarmiento ya había observado en el siglo XIX, es decir, la tensión entre dos sociedades que parecen dos pueblos diferentes ${ }^{45}$.

\section{La historia disgregada}

Mostrar las problemáticas latinoamericanas en clave estética no significa en Kusch un esfuerzo por capturar la cuestión bajo una disciplina determinada, sino el esfuerzo por interpretarlas a partir de sus propias expresiones. El drama mestizo como interpretación estética es en definitiva la denuncia de un sufrimiento social que ha sido parte constitutiva de nuestras sociedades, y que por su propia naturaleza amerita de un aparato categorial compatible con su origen. En este sentido las afirmaciones que hemos recogido de Sarmiento y Bilbao dan cuenta

\footnotetext{
45 Una cosa es la tensión real entre dos maneras de estructurarse socialmente y otra la apariencia de ser dos pueblos. Para Kusch todo sería parte de un movimiento dialéctico que da unidad metafísica a la historia americana: desde la figura mítica del Quetzalcóatl -la serpiente emplumada- que no concilia el cielo con la tierra, hasta la ciudad mestiza que no concilia el origen del pueblo -su ethos-y su institucionalidad. Cf. La Seducción de la Barbarie, especialmente los apartados "La Conciliación Mestiza" y "La Redención Mestiza".
} 
de este abordaje, porque en ambos el binomio civilización-barbarie conlleva necesariamente una visión de este tipo. Sin embargo la idea de un drama social va mucho más allá de una denuncia puntual en el tiempo, porque implica claramente una interpretación de nuestra historia y el modo en que los actores han vivido y expresado este drama, porque este hecho constituye nuestro propio devenir histórico, es decir, nuestro modo de estructurarnos como sociedades a partir de la separación entre una autoctonía negada y los anhelos de nuestras elites gobernantes.

El giro que implica llevar la problemática social latinoamericana al nivel del acontecer, significa precisamente reflexionar sobre la integridad de esa historicidad y las razones que han llevado a la reafirmación constante del quiebre con un "pasado" y el desconocimiento de su influencia en el presente y el futuro.

Para Kusch esta tensión se da básicamente entre lo indígena y el hijo del inmigrante, el primero vinculado con lo muerto y el segundo vinculado con lo vivo ${ }^{46}$, es decir, entre algo absolutamente pasado y algo absolutamente presente. Pero no se trata de una oposición ingenua, sino el resultado de un tipo específico de racionalidad occidental que con base en una pretendida objetividad científica considera al indio como un objeto dentro de un mundo en el cual evidentemente no tiene lugar ${ }^{47}$. En este sentido la arqueología ha contribuido a desnutrir lo indígena, dando un lugar protagónico en la historia únicamente a lo inmigrante, relegando lo indígena al museo; por otra parte la historia hace desaparecer lo indígena con el descubrimiento, conformando una versión de la historicidad americana como un proceso inequívoco de occidentalización ${ }^{48}$.

Sin embargo esta postura objetiva no radica simplemente en transformar al indio en un elemento dentro del mundo occidental, porque

46 KUSCH, Rodolfo. Anotaciones para una Estética de lo Americano (1955), en "Obras Completas", Tomo IV, $1^{\circ}$ Edición, Ed. Fundación Ross, Argentina, 2000. Pág. 785.

47 Anotaciones para una Estética de lo Americano, pág. 786.

48 Cf. Anotaciones para una Estética de lo Americano, pág. 785 y 786. 
más allá de esto está el trasfondo de esta actitud. A juicio de Kusch la objetividad occidental es en el fondo una "filosofía del objeto utilizable" ${ }^{\prime 4}$, porque a partir de las pautas que entrega la filosofía moderna, la realidad comienza a ser considerada como algo reconstruible, y no simplemente como una "representación del mundo", porque tiene como resultado inevitable la instrumentalización de todo aquello diferente a partir de la utilidad que pueda prestar al sujeto. Esta visión del mundo resultado de una objetivación de la realidad y la instauración de un sujeto gravitante, conforma un paradigma en el cual el indio no presta ninguna utilidad, al contrario, parece transformarse en una mancha dentro de un espacio que pretendía estar vacío y dispuesto absolutamente para el hombre occidental, por eso que dentro de esta concepción el indio "no tiene ninguna validez política, social o artística" ${ }^{50}$, porque no aporta mayormente a tales propósitos, es decir, no entra vitalmente a formar parte de dicho ámbito.

A juicio de Kusch nuestras naciones se crean a partir del sujeto, a partir de categorías y en un espacio geográfico teóricamente vací ${ }^{51}$, dicho de otra manera, nuestras naciones se crean a partir de la utilidad que los elementos puedan brindar a una inteligencia rectora y configuradora de la realidad, sin considerar que las ideas que deben guiar estas intenciones deben surgir de la misma realidad de hecho y no a partir de elementos asumidos de antemano como los más adecuados a los propósitos, y que finalmente han omitido las características propias de un pueblo que se ha forjado en una estrecha relación con el suelo que habita. Pero Kusch, a pesar de todo, considera que aún sobrevive un elemento:

Pero este proceso iniciado por la fuerza de las armas, primero, y luego mantenido por el historiógrafo y el arqueólogo, no impidió, en el terreno de lo político, la supervivencia, no ya del indio, sino de lo indígena, en su sentido literal de lo autóctono. Pudo desapa-

Ídem.

51 Ídem. 
recer, en el caso de Argentina, lo indio como cosa, pero no como estructura ${ }^{52}$.

Las palabras de Kusch son sugerentes porque hacen un giro desde indio como objeto a lo indígena como elemento político, dando cuenta de la sobrevivencia de este elemento autóctono como parte estructural de nuestra vida política. Ahora no se trata del indio debilitado por la historia y la arqueología -y las armas por cierto-, sino la continuidad de lo autóctono -que denominamos "lo indígena"- en nuestro presente. Esta interpretación sugiere a nuestro pensador la necesidad de recuperar positivamente este elemento para sincerar y sanear nuestra vida social, no a través de una historia que intente rescatar este elemento "pasado" como un elemento "presente", sino a través de una historia como estética que drene "la plenitud vivida en el pasado como mito y que se hace necesario en un presente sin finalidad como el nuestro" ${ }^{\prime \prime 3}$.

La idea de una historia como estética implica al menos dos cosas: la primera es la posibilidad de buscar ese pasado como un factor efectivo de nuestro presente y poder integrar como un todo nuestra historicidad, y en segundo lugar otorgar un sentido al presente a partir del rastreo de lo formal en el pasado ${ }^{54}$. Este último punto es de especial importancia, porque implica recoger de un habitar original una manera de formalizar la vida que ha sido permanentemente ignorada, porque ha sido valorizada como inferior, inviable, o simplemente como inexistente, es decir, bárbara, o ausente de toda forma.

En este sentido el arte adquiere un lugar de privilegio, porque es el paso de un contenido indeterminado a la adopción una forma determinada ${ }^{55}$. La expresión es la ruptura de una resistencia intrínseca de la materia a través del artista que es el artífice de ese paso, el vehículo que lleva un

52 Ídem.

53 Anotaciones para una Estética de lo Americano, pág. 787.

54 Cf. Ídem.

55 Cf. Anotaciones para una Estética de lo Americano, pág. 782. 
caos original a la fijación y visibilización a través del material utilizado. Estas observaciones kuschianas sobre el proceso artístico serán en definitiva la descripción de toda nuestra problemática social, porque a su juicio el problema del arte en Latinoamérica es el problema de su vida política, social y económica ${ }^{56}$, por tanto la representación total del drama mestizo. Sobre esta afirmación Kusch piensa que la vida de la comunidad se halla por debajo de la estructura de poder, subvirtiendo las "formas" que conscientemente se han intentado levantar, revelándolas como un canon arbitrario que pretende subsumir la verdadera vida a través de un marco rígido que la fija en una forma exógena ${ }^{57}$.

El arte oficial surge de un miedo original hacia lo informe y caótico de la barbarie, resultando una manifestación formal y estable que evita a toda costa un contacto contaminador con lo de "abajo", de ahí que la actividad artística, y por tanto política, social y cultural, sean una actividad de apariencias. En este sentido, bajo una moral de fuga, se tiende a sobrestimar el aspecto visible y formal -como en Sarmiento-, en contraste con lo invisible y caótico, por ello se da prioridad absoluta al producto y no a la génesis de ese producto, es decir, vale más la obra que el artista, vale más el resultado práctico que el sentido genético de ese resultado, por tanto una estética de lo americano no podría transformarse en una estética del arte, sino en una estética del acto artístico, es decir, del paso de la vivencia del artista a la obra, de la vida como absoluto a la incrustación en la sociedad, por tanto, de la vida a la política, de la vida a las instituciones, de la vida a la economía. Una historia como estética, por tanto, brinda la posibilidad de levantar un puente entre el caos y la forma, la emoción y la razón, pero no en una sujeción definitiva, sino en la permanente actualización de ese vínculo a través de la eterna renovación de esos profundos planteos vitales, rompiendo con la escisión entre ésta y su manifestación visible.

Es por ello que el problema del arte es en esencia el problema de nuestra vida social, no sólo por la "obra" visible y permanente que

56 ídem.

57 Anotaciones para una Estética de lo Americano, pág. 780. 
nuestros próceres intentaron construir con la materia aparentemente informe de nuestros pueblos ${ }^{58}$, sino también porque el verdadero arte nos da una lección sobre el proceso efectivo que lleva de la materia a la forma, de ahí que sea "una respuesta plástica a la pregunta primordial que el grupo social -por intermedio del artista- se ha hecho sobre sí mismo" ${ }^{59}$, porque pone en crisis la inercia social que caracteriza la formalidad de nuestras instituciones. Kusch afirma:

Mientras el cuerpo social deambula dentro de su propia estructura intelectual, la vida le cuestiona sus derechos por intermedio del arte $^{60}$.

El producto artístico en sí mismo, como evasión de la vitalidad, se vale formalmente ya sea del instrumento o el material utilizado, pero esto es el momento segundo del arte, su concreción en la sociedad, su visibilidad, porque lo más importante es lo "invisible" que lo constituye, pues sin ello cae en manos de una creación sin sentido y sin propósito, como puro juego. Este fenómeno lúdico pasa a ser el corazón de toda actividad social, porque así como los niños juegan seriamente a ser su personaje favorito, de la misma manera la simulación del juego, el "hacer como si...", se transforma en una verdad absoluta, olvidando precisamente la intencionalidad lúdica, transformándose en una actividad que se revuelve sobre sí misma emulando a otra cultura: construyendo casas como..., vistiéndose como..., pensando como..., haciendo política como..., promoviendo cultura como... etc.

En el sentido opuesto, el gran arte es la manifestación verdadera de esa vitalidad, su corolario, pero ésta no necesariamente se ha descargado en planos netamente artísticos o en los grandes escenarios, sino en la marginalidad, pero ni siquiera en el sentido de glorificación, sino como

58 Martínez Estrada afirma que "La barbarie no es un estado accidental; tiene sus normas, sus leyes, su moral consuetudinaria, sus arranques potentes de invención -muy viejos". MARTíNEZ ESTRADA, Ezequiel. Radiografía de la Pampa (1933), $1^{\circ}$ Edición, Ed. Losada, Buenos Aires, 2007. Pág. 86.

59 Anotaciones para una Estética de lo Americano, pág. 783.

60 ídem. 
manifestación de la miseria que marca la escisión definitiva entre lo oficial y lo popular, entre lo formal y lo caótico ${ }^{61}$.

La antinomia que se manifiesta en el arte a partir de su sentido genético se apareja totalmente con nuestros problemas sociales, porque es la misma distancia entre lo vital y lo estructural; es la distancia del suburbio al centro, del campo a la ciudad, del individuo a la sociedad, y dentro de cada uno, de la vida a la razón, pero considerado a nivel político es la separación inconciliable entre la comunidad y los gobernantes. Es la escisión entre un Ethos autóctono y el sentido de fuga que le hemos dado al poder y a la organización de nuestras sociedades, disgregando nuestra historia en dos vectores paralelos.

La respuesta plástica que nos entrega el arte hace comprensibles y visibles aquellos elementos vitales que fueron relegados a la marginalidad, porque vuelve a traducir en formas y signos adecuados para nuestra sociedad, todo aquello que sigue siendo considerado bárbaro y primitivo. El ejemplo de Kusch es el Fausto de Goethe, porque llevará a la conciencia de la burguesía alemana de la época una actualización de la vida que fue sentida como un complejo vital.

Pero más allá de la cuestión sobre lo indígena como elemento político y su peso sobre nuestras sociedades, está la reflexión sobre la resistencia o la ortodoxia del sentir formal de nuestra vida ${ }^{62}$, porque toca el problema de la formalidad como principio, tal como lo mostramos en Sarmiento y Bilbao, o bien recordando las intenciones de Benjamín Vicuña Mackenna por europeizar Santiago ${ }^{63}$, cuestiones que finalmente han marcado nuestra vida social con una tensión aparentemente insuperable entre la civilización y la barbarie, es decir, entre la forma y la materia. Sin embargo la idea de una historia como estética ambiciona la posibilidad de rastrear un sentido de la vida que vaya más allá del refugio arbitrario y acrítico en la forma, centrándose en la "calibración de esta forma y de este espíritu en fun- 
ción de la vivencia del mal y de lo amorfo, como si éstos se adosaran dialécticamente al del bien y de la forma" ${ }^{64}$, es decir, va en búsqueda de una coordinación de la vida y su formalización, como el encuentro de oposiciones que dialécticamente superan la negación del otro:

Es la apreciación del supuesto mal como fermento del bien que llevaría a encontrar en lo amorfo una forma propia. Una manera herética de encontrar dentro de lo bárbaro a la civilización ${ }^{65}$.

\section{Conclusión}

La intención de Kusch al centrar sus esfuerzos interpretativos en el mundo indígena y popular, no es una reivindicación ingenua del pasado tal como lo estudia el historiador, sino la visibilización del elemento autóctono como factor político, social, cultural, económico, etc., gravitante, tal como lo reconocía negativamente Sarmiento y Bilbao. Por lo mismo el trabajo de Kusch debería inscribirse dentro de los pensadores fundacionales, no sólo por seguir una línea de pensamiento que viene desde nuestros orígenes como repúblicas independientes, sino porque intenta reconstruir el tejido social a partir del elemento constituyente del pueblo, es decir, su propia gente y el sentido latente que debería nutrir permanentemente toda institucionalidad y la posibilidad de hacer una historia en conjunto.

\section{Bibliografía}

BILBAO, Francisco. Sociabilidad Chilena (1844), en "Francisco Bilbao; el Autor y su Obra", $1^{\circ}$ Edición, Editor José Alberto Bravo, Ed. Cuarto Nuevo, Chile, 2007.

JALIF, Clara. Francisco Bilbao y la Propuesta Libertaria de América, $1^{\text {a }}$ Edición, Ed. Universidad Nacional de Cuyo, Mendoza, 2003.

64 Anotaciones para una Estética de lo Americano, pág. 788.

65 Ídem (subrayado nuestro). 
KUSCH, Rodolfo. Inteligencia y Barbarie (1954), en "Obras Completas" Tomo IV, $1^{\circ}$ Edición, Ed. Fundación Ross, Argentina, 2000.

Seducción de la Barbarie: Análisis Herético de un Continente Mestizo (1953), en "Obras Completas" Tomo I, 1ª Edición, Ed. Fundación Ross, Argentina, 2000.

Geocultura del Hombre Americano (1975), en "Obras Completas" Tomo III, 1ª Edición, Ed. Fundación Ross, Argentina, 2000. Una Lógica de la Negación para Comprender a América, en "Obras Completas", Tomo II, 1ª Edición, Ed. Fundación Ross, Argentina, 2000.

Anotaciones para una Estética de lo Americano (1955), en "Obras Completas", Tomo IV, $1^{\text {a }}$ Edición, Ed. Fundación Ross, Argentina, 2000.

MARTínEZ ESTRADA, Ezequiel. Radiografía de la Pampa (1933), 1ª Edición, Ed. Losada, Buenos Aires, 2007.

SARMIENTO, Domingo Faustino. Facundo o Civilización y Barbarie en las Pampas Argentinas (1845), Edición digital, Ed. elaleph.com, 1999.

Ambas Américas; Revista de Educación, Bibliografía y Agricultura (1867), Edición digital, Editor Domingo Faustino Sarmiento, New York, 1867.

WEHNER, Leslie. Génesis de la Transformación de Santiago, Tesis de Grado para optar al grado de Licenciada en Historia, Universidad Católica de Chile, Chile, 2000. 